ARTIKEL

\title{
ANALISIS ATAS KEBIJAKAN PEMERINTAH TENTANG BPJS DAN JKN MELALUI UU 36 TAHUN 2009 TENTANG KESEHATAN
}

\author{
Cucu Sugyati \\ Universitas Padjadjaran \\ susantiq@yahoo.co.id
}

\begin{abstract}
This study seeks to make a deep systematic analysis of the involvement of the community as an additional implementing element in the implementation of public health policy, especially in the field of mother and child in West Java, Indonesia. This descriptive-qualitative study presents a discussion of how the elements of public health practitioners interact with communities in West Java Province so that their knowledge and skills are needed. With the theory of health services, data obtained that (a) service and network cooperation in public health institutions, within the Provincial Government of West Java is quite uniform and well implemented; (b) in carrying out its obligations as the implementing element of the community deeply understand public policy in the field of public health, especially maternal and child health; so they can carry out their functions to serve the community. Nevertheless, the lack of community volunteers directly addressing maternal and child health is felt so that this review recommends incentives for health workers coming from ordinary people.

Keyword: Public Health, Mother-Child Health, Public Policy Implementation
\end{abstract}

Abstrak

Kajian ini berupaya membuat analisis sistematis yang mendalam terhadap keterlibatan masyarakat sebagai unsur pelaksana tambahan dalam implementasi kebijakan kesehatan masyarakat terutama bidang ibu dan anak di wilayah Jawa Barat, Indonesia. Kajian deskriptif-kualitatif ini menghadirkan pembahasan tentang bagaimana unsur-unsur pelaksana kesehatan masyarakat berinteraksi dengan masyarakat di Provinsi Jawa Barat sehingga pengetahuan dan keterampilan mereka sangat diperlukan. Dengan teori pelayanan kesehatan, didapatkan data bahwa (a) pelayanan dan jaringan kerja sama di lembaga kesehatan masyarakat, di lingkungan Pemerintah Provinsi Jawa Barat sudah cukup seragam dan terlaksana dengan baik; (b) dalam melaksanakan kewajibannya sebagai unsur pelaksana masyarakat sangat memahami kebijakan publik di bidang kesehatan masyarakat, terutama kesehatan ibu dan anak; sehingga dapat melaksanakan fungsi mereka untuk melayani masyarakat. Namun demikian, kurangnya tenaga sukarela masyarakat yang langsung menangani kesehatan ibu dan anak dirasakan sehingga kajian ini merekomendasikan untuk diadakannya insentif-insentif bagi para petugas kesehatan yang berasal dari masyarakat biasa.

Kata Kunci: Kesehatan Masyarakat, Kesehatan Ibu-Anak, Implementasi Kebijakan Publik.

\section{A. PENDAHULUAN}

Kesehatan merupakan salah satu kebutuhan dasar bagi kehidupan individu, keluarga dan kelompok masyarakat yang dicapai melalui berbagai upaya kesehatan. Berbagai upaya kesehatan yang diselenggarakan oleh berbagai pihak merupakan rangkaian pembangunan bidang kesehatan. Di Indonesia, pembangunan bidang 
kesehatan merupakan pengejawantahan Pasal 28 ayat (1) Undang-Undang Dasar Tahun 1945 yang menyatakan bahwa setiap orang berhak memperoleh pelayanan kesehatan, dan Pasal 34 ayat (3) menyatakan bahwa negara bertanggung jawab atas penyediaan fasilitas pelayanan kesehatan dan fasilitas pelayanan umum yang layak.

Guna melaksanakan pembangunan bidang kesehatan secara efektif jelas dibutuhkan dukungan sumber daya bidang kesehatan sebagaimana diamanatkan pada Pasal 1 Undang-Undang Nomor 36 Tahun 2009 tentang Kesehatan. Sumber daya di bidang kesehatan adalah segala bentuk dana, tenaga, perbekalan kesehatan, persediaan farmasi dan alat kesehatan serta fasilitas pelayanan kesehatan dan teknologi yang dimanfaatkan untuk menyelenggarakan upaya kesehatan yang dilakukan oleh Pemerintah, pemerintah daerah, dan/atau masyarakat.

Dukungan sumber daya bidang kesehatan tersebut sangat dibutuhkan dalam penyelenggaraan pemerintahan daerah. Tujuan penyelenggaraan pemerintahan daerah sebagaimana diatur dalam Undang-Undang Nomor 23 Tahun 2014 tentang Pemerintahan Daerah adalah mewujudkan kesejahteraan masyarakat.

Penurunan atau rendahnya derajat kesehatan antara lain tampak dari perilaku hidup yang kurang sehat, rendahnya kesadaran untuk memelihara kebersihan dan kesehatan lingkungan, menurunnya kesehatan individu dan keluarga, gizi buruk, dan berjangkitnya penyakit-penyakit menular. Dampak dari rendahnya derajat kesehatan tentu tidak terbatas hanya pada kehidupan individu dan keluarga. Kehidupan sosial masyarakat pun bisa terdampak dari menurunnya derajat kesehatan. Karena itu, diperlukan berbagai pendekatan pembangunan kesehatan untuk melakukan upaya kesehatan. Tujuan upaya kesehatan sebagaimana dinyatakan dengan Pasal 3 UndangUndang Nomor 36 Tahun 2009 tentang Kesehatan adalah meningkatkan kesadaran, kemauan dan kemampuan hidup sehat bagi setiap orang agar terwujud derajat kesehatan masyarakat yang optimal melalui pemeliharaan kesehatan dan pencegahan penyakit.

Peningkatan derajat kesehatan masyarakat antara lain dicapai dengan menyelenggarakan pelayanan kesehatan masyarakat. Untuk menyelenggarakan pelayanan kesehatan masyarakat yang efektif, Pemerintah telah menerbitkan Peraturan Menteri Kesehatan Nomor 741/MENKES/PER/VII/2008 tentang Standar Pelayanan Minimal Bidang Kesehatan. Pasal 2 ayat (2) Permenkes menyatakan: "Jenis 
pelayanan bidang kesehatan mencakup: pelayanan kesehatan dasar (kunjungan ibu hamil, komplikasi kebidanan, pertolongan persalinan, nifas, neonatus, imunisasi anak, anak balita, makanan pendamping ASI, balita gizi buruk, kesehatan siswa, peserta KB, pelayanan masyarakat miskin), pelayanan kesehatan rujukan (pasien masyarakat miskin dan gawat darurat level 1), epidemiologi dan penanggulangan KLB, serta promosi kesehatan dan pemberdayaan masyarakat)."

Meskipun penyelenggara pelayanan kesehatan dilakukan juga oleh pihak swasta, namun untuk mengefektifkan pelayanan kesehatan dasar yang meliputi kunjungan ibu hamil, komplikasi kebidanan, pertolongan persalinan, nifas, neonatus, imunisasi anak, anak balita, makanan pendamping ASI, balita gizi buruk, kesehatan siswa, peserta KB, pelayanan masyarakat miskin, Pemerintah Daerah perlu memperluas penyediaan infrastruktur pelayanan kesehatan. Untuk itu, Pemerintah Daerah mendirikan Rumah Sakit Umum Daerah (RSUD) dan Pusat-pusat Kesehatan Masyarakat (Puskesmas) serta memotivasi masyarakat untuk menyelenggarakan Pos-pos Pelayanan Terpadu (Posyandu) di lingkungan RT dan RW setempat. Fungsi Posyandu yang dilaksanakan oleh Tim Penggerak PKK atau kelompok-kelompok perempuan lainnya merupakan salah satu bentuk partisipasi masyarakat dalam upaya kesehatan.

Upaya kesehatan masyarakat yang diselenggarakan oleh Pemerintah Daerah merupakan pelaksanaan Pasal 12 ayat (1) Undang-Undang Nomor 23 Tahun 2014 Tentang Pemerintahan Daerah. Ayat tersebut menyatakan bahwa urusan pemerintahan wajib yang berkaitan dengan pelayanan dasar antara lain pelayanan kesehatan. Terkait dengan kebijakan ini, Pemerintah telah menerbitkan Peraturan Pemerintah Nomor 65 Tahun 2005 tentang Pedoman Penyusunan Standar Pelayanan Minimal, Peraturan Pemerintah Nomor 6 Tahun 2007 tentang Petunjuk Teknis Penyusunan dan Penetapan Standar Pelayanan Minimal, dan secara khusus, standar pelayanan minimal di rumah sakit diatur dengan Keputusan Menteri Kesehatan Nomor: 129/Menkes/SK/II/2008 tentang Standar Pelayanan Minimal Rumah Sakit. Dalam konteks inilah, maka kualitas pelayanan kesehatan dasar menjadi penting sekali dalam mendukung terwujudnya kesejahteraan masyarakat.

Untuk pelayanan kepada masyarakat yang memuaskan, maka pemerintah membuat Badan Usaha Milik Negara, yaitu Badan Penyelenggara Jaminan Sosial (BPJS). Namun demikian, keberadaannya, strukturnya, pelayanan dan cara 
beroperasinya masih sangat perlu untuk disosialisasikan. Di sinilah perlunya pihakpihak terkait dengan kesehatan masyarakat, baik itu pemerintah melalui dinas-dinas kesehatannya maupun pihak dunia usaha pelayanan seperti BPJS melakukan sosialisasi. Dan sosialisasi yang paling massif kepada masyarakat dapat memakai media massa.

\section{B. TINJAUAN TEORETIK}

Sejalan dengan amanat Pasal $28 \mathrm{H}$ ayat (1) Undang-Undang Dasar Negara Republik Indonesia Tahun 1945 telah ditegaskan bahwa setiap orang berhak memperoleh pelayanan kesehatan, kemudian dalam Pasal 34 ayat (3) dinyatakan negara bertanggung jawab atas penyediaan fasilitas pelayanan kesehatan dan fasilitas pelayanan umum yang layak.

Mengacu pada penjelasan pasal tersebut, instansi kesehatan termasuk salah satu upaya kesehatan yang disediakan oleh pemerintah, seperti halnya Pemerintah Provinsi Jawa Barat untuk ditingkat Kabupaten/Kota Kecamatan dan Kelurahan/Desa. Selanjutnya dalam penyelenggaraan upaya kesehatan tersebut berpedoman pada Peraturan Menteri Kesehatan Nomor 741/MENKES/PER/VII/2008 tentang Standar Pelayanan Minimal Bidang Kesehatan di Kabupaten/Kota. Standar Pelayanan Minimal Bidang Kesehatan (SPM Kesehatan).

Dengan fungsi menyelenggarakan kegiatan pelayanan kesehatan yang menjangkau seluruh sasaran terutama sasaran pelayanan kesehatan di kalangan masyarakat yang tidak mampu. Dengan demikian Pemerintah Provinsi Jawa Barat mendirikan Pusat-pusat Kesehatan Masyarakat sebagai ujung tombak pelayanan kesehatan masyarakat. Fungsi Puskesmas ini juga terkait erat dengan pelaksanaan fungsi Pos-pos Pelayanan Terpadu (Posyandu) yang dilaksanakan oleh Tim Penggerak PKK di lingkungan RT, RW, Desa/Kelurahan setempat (Anwar et.al., 2018).

Upaya kesehatan masyarakat yang diselenggarakan oleh Pemerintah Daerah merupakan pelaksanaan Pasal 11 ayat (4) Undang-Undang Nomor 32 Tahun 2004 yang menyatakan bahwa "Penyelenggaraan urusan yang bersifat wajib yang berpedoman pada standar pelayanan minimal dilaksanakan secara bertahap dan ditetapkan oleh Pemerintah”. Untuk itu, Pemerintah menerbitkan Peraturan Pemerintah Nomor 65 Tahun 2005 tentang Pedoman Penyusunan Standar Pelayanan Minimal, Peraturan Pemerintah Nomor 6 Tahun 2007 tentang Petunjuk Teknis Penyusunan dan 
Penetapan Standar Pelayanan Minimal, dan secara khusus, standar pelayanan minimal di rumah sakit diatur dengan Keputusan Menteri Kesehatan Nomor: 129/Menkes/SK/II/2008 tentang Standar Pelayanan Minimal Rumah Sakit. Dalam konteks inilah, maka implementasi kebijakan standar pelayanan minimal menjadi penting dan menentukan kualitas pelayanan kesehatan (Anwar et.al., 2018).

Untuk itu, kebijakan dan kegiatan pelayanan kesehatan perlu diarahkan dan dioptimalisasikan untuk meningkatkan pengetahuan masyarakat akan pentingnya kesehatan. Sementara itu, pelayanan kesehatan yang optimal hanya bisa diselenggarakan apabila sumber daya pelayanan kesehatan dapat terpenuhi. Sumber daya kesehatan yang dimaksud tentu tidak hanya pada penyediaan tenaga kesehatan saja, tetapi mencakup pula sumber daya kesehatan lainnya seperti penyediaan anggaran pelayanan kesehatan, penyediaan sarana dan prasarana pelayanan kesehatan dan penggunaan teknologi kesehatan yang kini semakin canggih dan lengkap. Pada satu sisi, penyediaan sumber daya kesehatan tersebut dapat terpenuhi oleh institusi-institusi pelayanan kesehatan yang diselenggarakan oleh pihak swasta. Namun biaya untuk memperoleh pelayanan kesehatan yang diselenggarakan oleh pihak swasta dianggap jauh lebih bermutu dan sangat mahal bila dibandingkan dengan pelayanan kesehatan yang diselenggarakan oleh instansi pemerintah.

Menurut Azwar (1996), ada syarat-syarat pokok pelayanan kesehatan yang harus dipenuhi agar dapat dikatakan sebagai pelayanan kesehatan yang baik, yaitu:

1. Tersedia dan berkesinambungan.

2. Dapat diterima dan wajar.

3. Mudah dicapai, terutama dari sudut lokasi.

4. Mudah dijangkau, terutama dari sudut biaya.

5. Bermutu.

Dalam kontek pemanfaatan pelayanan kesehatan adalah merupakan interaksi antara konsumen dengan pemberi pelayanan. Beberapa faktor yang memengaruhi pemanfaatan pelayanan kesehatan yaitu faktor yang berhubungan sosiokultural, faktor organisasi, penerima layanan dan faktor pemberi pelayanan.

Faktor sosiokultural terdiri dari teknologi dan nilai-nilai sosial yang ada di masyarakat. Kemajuan teknologi dapat dapat meningkatkan pemanfaatan pelayanan kesehatan seperti transplantasi jantung, ginjal, penemuan organ-organ buatan, serta 
ARTIKEL

kemajuan dibidang radiologi (Dever, 1984). Dalam kontek ini, juga mempertimbangkan kearifan lokal termasuk norma, nilai dan keyakinan yang ada di masyarakat. Hal ini akan mempengaruhi seseorang dalam bertindak termasuk dalam upaya memanfaatkan pelayanan kesehatan.

Selanjutnya faktor-faktor yang berhubungan dengan organisasi adalah struktur dan proses yang memberi kebijakan kepada organisasi pelayanan kesehatan dan lingkungan sekitar yang memengaruhi proses perawatan kesehatan. Faktor-faktor tersebut adalah ketersediaan sumber daya, akses geografi, akses sosial serta karakteristik struktur dan proses perawatan (Dever, 1984).

\section{METODE PENELITIAN}

Obyek penelitian ini adalah kebijakan pemerintah tentang BPJS dan JKN dan implementasinya di Provinsi Jawa Barat. Pendekatan penelitian yang digunakan di sini berdasarkan paradigma penelitian kualitatif dengan metode analisis deduktif. Pendekatan penelitian ini dipilih dengan alasan bahwa penelitian kualitatif dengan metode tersebut merupakan pendekatan penelitian yang menonjolkan penggalian obyek permasalahan secara mendalam (Denzin and Lincoln, 1994: 66).

Menurut Creswell (2012) paradigma penelitian kualitatif pada hakikatnya berasal dari Antropologi Budaya dan Sosiologi Amerika. Hanya baru-baru ini saja paradigma tersebut diadopsi oleh para peneliti pendidikan (Borg \& Gall, 1989). Tujuan penelitian kualitatif adalah memahami situasi, peristiwa, kelompok, atau interaksi sosial tertentu (Locke, Spirduso, \& Silverman, 1987). Penelitian ini dapat diartikan sebagai proses investigatif yang di dalamnya peneliti secara perlahan-lahan memaknai suatu fenomena sosial dengan membedakan, membandingkan, menggandakan, mengatalogkan, dan mengklasifikasikan objek penelitian (Miles \& Huberman, 1994). Marshall dan Rossman (1989) menyatakan bahwa penelitian ini melibatkan peneliti untuk menyelami setting peneliti. Peneliti memasuki dunia informan melalui interaksi berkelanjutan, mencari makna-makna dan perspektif-perspektif informan.

\section{HASIL DAN PEMBAHASAN}

Pelayanan kesehatan ibu dan anak di Provinsi Jawa Barat tampaknya masih belum optimal. Belum optimalnya pelayanan kesehatan ibu dan bayi tentu berdampak luas. Dampak belum optimalnya secara kuantitatif pelayanan kesehatan ibu dan bayi di 
Provinsi Jawa Barat antara lain terungkap dari data kesehatan Provinsi Jawa Barat yang menunjukan bahwa pada tahun 2015 saja di Provinsi Jawa Barat terdapat 71.805 bayi lahir yang dirujuk karena terlahir dengan kondisi Berat Badan Lahir Rendah (BBLR). Sementara itu, jumlah bayi yang mengalami gizi buruk di Provinsi Jawa Barat pada tahun 2015 mencapai 2.979 bayi atau 0,30 persen dari total bayi yang lahir pada tahun yang sama sebanyak 988.356 bayi. Dengan demikian, pelayanan kesehatan ibu dan anak di Provinsi Jawa Barat, sebagai suatu fenomena kinerja pelayanan kesehatan yang dilakukan instansi kesehatan di Provinsi Jawa Barat layak dikritisi (Sugyati et.al., 2018).

Mengacu pada persoalan kualitas pelayanan kesehatan, upaya kesehatan masyarakat yang diselenggarakan oleh Pemerintah Daerah merupakan pelaksanaan Pasal 11 ayat (4) Undang-Undang Nomor 32 Tahun 2004 yang menyatakan bahwa "Penyelenggaraan urusan yang bersifat wajib yang berpedoman pada standar pelayanan minimal dilaksanakan secara bertahap dan ditetapkan oleh Pemerintah". Untuk itu, Pemerintah menerbitkan Peraturan Pemerintah Nomor 65 Tahun 2005 tentang Pedoman Penyusunan Standar Pelayanan Minimal, Peraturan Pemerintah Nomor 6 Tahun 2007 tentang Petunjuk Teknis Penyusunan dan Penetapan Standar Pelayanan Minimal, dan secara khusus, standar pelayanan minimal di rumah sakit diatur dengan Keputusan Menteri Kesehatan Nomor: 129/Menkes/SK/II/2008 tentang Standar Pelayanan Minimal Rumah Sakit. Dalam konteks inilah, maka implementasi kebijakan standar pelayanan minimal menjadi penting dan menentukan kualitas pelayanan kesehatan (Anwar et.al., 2018).

Kendati standar pelayanan minimal di bidang kesehatan sudah diterbitkan, namun bukan berarti tujuan pembangunan bidang kesehatan sebagaimana dinyatakan dalam Undang-Undang Nomor 36 Tahun 2009 tentang Kesehatan dapat tercapai secara optimal. Demikian karena setiap orang berhak atas jaminan sosial untuk dapat memenuhi kebutuhan dasar hidup yang layak dan meningkatkan martabatnya menuju terwujudnya masyarakat Indonesia yang sejahtera, adil, dan makmur. Sesuai dengan Undang- Undang No. 40 Tahun 2004 tentang Sistem Jaminan Sosial Nasional (SJSN), jaminan sosial adalah salah satu bentuk perlindungan sosial untuk menjamin seluruh rakyat agar dapat memenuhi kebutuhan dasar hidup dan pekerjaan yang layak. Jaminan sosial berhubungan dengan kompensasi dan program kesejahteraan yang diselenggarakan pemerintah untuk seluruh rakyat Indonesia (Sugyati et.al., 2018). 
Untuk menjamin terselenggaranya tujuan SJSN tersebut, maka disahkan Undang-Undang No. 24 Tahun 2011 tentang Badan Penyelenggara Jaminan Sosial (BPJS). BPJS merupakan badan hukum yang memiliki tujuan mewujudkan terselenggaranya pemberian jaminan sosial bagi setiap peserta dan anggota keluarganya. Dalam penyelenggaraannya, BPJS ini terbagi menjadi dua, yaitu BPJS Kesehatan dan BPJS Ketenagakerjaan. Penyelenggaraan SJSN di Indonesia mulai berlaku sejak 1 Januari 2014, diawali dengan program jaminan kesehatan (Mulyadi, 2014).

PT Askes dan PT Jamsostek yang ditunjuk sebagai lembaga penyelenggara BPJS kemudian beralih bentuk dalam upaya menjalankan fungsi BPJS. PT Askes resmi menjadi badan hukum publik BPJS Kesehatan pada awal 2014 dan PT Jamsostek beralih menjadi badan hukum publik BPJS Ketenagakerjaan pada 1 Juli 2015 (Indonesia J., 2015).

Pada awal pelaksanaan Jaminan Kesehatan Nasional (JKN) 1 Januari 2014, setidaknya ada 121,6 juta peserta yang terdiri dari peserta asuransi kesehatan sosial PT Askes (pegawai negeri sipil/PNS dan pensiunan beserta keluarga, anggota dan pensiunan TNI/Polri dan keluarga), peserta jaminan kesehatan dari PT Jamsostek, perserta yang berasal dari semua BUMN, serta penduduk miskin yang tercakup dalam Jaminan Kesehatan Masyarakat (Jamkesmas) yang kemudian menjadi Penerima Bantuan Iuran (PBI) (Kesehatan, B.P.J.S., 2014).

Akan tetapi hingga saat ini, berbagai tantangan dan kendala bermunculan dalam upaya persiapan pelaksanaan BPJS. Salah satu tantangan yang dihadapi adalah sosialisasi ketentuan jaminan sosial. Program Jaminan Kesehatan Nasional (JKN) yang bertujuan meningkatkan derajat kesehatan masyarakat belum maksimal karena sosialisasi yang tidak optimal. Program BPJS masih membingungkan masyarakat, khususnya pengguna Jamkesmas dan Jamkesda. Bahkan, ada masyarakat yang menjadi panik dan takut tidak memperoleh pelayanan kesehatan BPJS karena tidak memiliki kartu Jamsostek dan Askes. Direktur Lembaga Perlindungan dan Pemberdayaan Konsumen Indonesia (LPPKI), Dr. Agus Kasiyanto, mengatakan, BPJS Ketenagakerjaan maupun BPJS Kesehatan perlu melakukan sosialisasi secara menyeluruh agar masyarakat lebih mengetahui ketentuan tentang jaminan kesehatan dan ketenagakerjaan (Mulyadi, 2014). 
ARTIKEL

Kurangnya sosialisasi JKN dirasakan baik oleh pelaksana maupun masyarakat penerima layanan secara umum. Program JKN yang dijalankan pemerintah ini sesungguhnya sangat baik. Namun, kesiapan Kementerian Kesehatan (Kemenkes) untuk secara aktif menggandeng Pemerintah Daerah (Pemda) mensosialisasikan program tersebut masih kurang seperti terlihat misalnya, disinyalir hampir 80 persen petugas kesehatan Sukabumi belum paham soal BPJS, karena memang belum pernah ada sosialisasi apalagi pelatihan untuk menjalankan program asuransi kesehatan pemerintah tersebut. Bahkan pada minggu pertama tahun 2014 unit layanan BPJS untuk masyarakat umum di Sukabumi belum beroperasi. Layanan kesehatan baru diberikan untuk PNS, pensiunan, dan TNI/ Polri sematamata karena petugas belum paham prosedur pelayanannya.

Selain lembaga pelaksana, sosialisasi kepada tenaga kesehatan juga masih belum memadai, baik dalam hal pelayanan maupun insentif yang diterima sebagai balasan performanya. Minimnya sosialisasi bukan hanya disebabkan oleh lemahnya koordinasi antarlembaga terkait, tapi juga faktor geografis yang menyulitkan akses kepada masyarakat di daerah pedalaman, seperti di Garut.

Peserta JKN banyak yang belum mengetahui prosedur kepesertaan. Ada peserta yang tidak mengetahui tempat pendaftaran kepesertaan. Ada juga yang kesulitan mengisi formulir BPJS online Hal ini karena tidak ada petugas yang memandu masyarakat untuk mempermudah proses pendaftaran.

Peserta juga belum mengetahui keuntungan apa yang diperoleh dengan mengikuti program atau perihal iuran premi yang harus dikeluarkan sebagai peserta JKN. Masyarakat menduga-duga premi yang harus dikeluarkan sehingga muncul kekhawatiran bahwa iuran ini akan memberatkan mereka. Selain itu, masih belum terinformasikan dengan baik mengenai tata cara penggunaan kartu BPJS saat peserta berobat di fasilitas kesehatan. Masyarakat yang sebelumnya memiliki akses layanan kesehatan Jamkesmas kebingungan sebab rumah sakit yang sebelumnya melayani mereka meminta kartu BPJS Kesehatan.

Untuk memberikan sosialisasi mengenai BPJS, Kementerian Kesehatan merilis Buku Pegangan Sosialisasi Jaminan Kesehatan (JKN) dalam Sistem Jaminan Sosial Nasional. Buku ini secara ringkas memuat informasi tentang JKN yang mencakup arti pentingnya skema jaminan kesehatan nasional serta mekanisme dan penyelenggaraan 
jaminan kesehatan nasional. Namun demikian, masih terdapat kebingungan di masyarakat luas, yakni pertama, dalam hal substansi informasi. Informasi yang disampaikan di media massa belum komprehensif meliputi aspek-aspek praktis yang dibutuhkan pengguna layanan. Iklan yang disampaikan di televisi tidak dapat menjelaskan segala hal mengenai BPJS.

Kedua, penggunaan media informasi yang belum tepat guna. Penggunaan media informasi memiliki dampak yang berbeda bagi penerimanya. Masyarakat dengan akses media elektronik dengan mudah menemukan informasi BPJS di internet atau televisi. Namun demikian, hal ini tidak berlaku bagi masyarakat dengan akses terbatas. Sosialisasi seharusnya dibuat dalam bentuk himbauan, penyuluhan, dan pengumuman di berbagai tempat yang dekat dengan masyarakat, terutama di rumah sakit dan puskesmas. Selain itu, pemerintah disarankan melakukan sosialisasi lebih intensif ke tempat-tempat umum dan pusat keramaian. Sosialisasi BPJS dapat dilakukan di mallmall, pasar-pasar, terminal, universitas, dan tempat keramaian lainnya.

Sosialisasi yang agak besar pernah dilakukan Presiden SBY namun gaungnya masih di bawah yang diharapkan, yakni pada saat peresmian Badan Penyelenggara Jaminan Sosial sebagai penyelenggaran JKN di Istana Bogor, Jawa Barat, pada hari Selasa 31 Desember 2013, dan tinjauan Presiden SBY bersama Ibu Ani Yudhoyono ke Puskesmas Pucang Sewu dan RSUD Dr Soetomo di Surabaya, Sabtu, 4 Januari 2014. Sementara itu, sosialisasi yang dilakukan para menteri tidak begitu massif. Yang ada hanyalah pernyataan-pernyataan singkat di media-media soal sudah berjalannya BPJS dan diberlakukan JKN sejak tahun baru (Kesehatan, B.P.J.S., 2014).

Masyarakat membutuhkan informasi yang pasti tentang teknis pelaksanaan BPJS Kesehatan, misalnya, informasi tentang manfaat, iuran dan pendaftaran kepesertaan. Salah satu hambatan penyampaian informasi seputar BPJS kepada masyarakat disebabkan oleh lambannya pemerintah menuntaskan regulasi operasional UU SJSN dan UU BPJS. Oleh karenanya, pemerintah dituntut segera menyelesaikan regulasi operasional BPJS dan menyampaikannya kepada masyarakat, apalagi jika kemudian kebijakan-kebijakannya bersifat berubah-ubah.

Kebijakan pemerintah tentang BPJS perlu diketahui dan dipahami oleh seluruh masyarakat Indonesia. Untuk itu perlu dilakukan penyebarluasan informasi melalui 
sosialisasi kepada semua pemangku kepentingan atau masyarakat pada umumnya. Sosialisasi ketentuan jaminan sosial penting dilakukan tidak hanya menyasar terhadap pelaksana saja tetapi juga bagi pengguna layanan sehingga JKN dapat digunakan secara optimal.

\section{E. SIMPULAN}

Berdasarkan hasil dan pembahasan penelitian dirumuskan simpulan penelitian sebagai berikut:

1. Pelaksanaan sosialisasi pelayanan kesehatan ibu dan anak di media yang dijalankan Dinas Kesehatan Jawa Barat tidak begitu massif, padahal dengan adanya program BPJS Kesehatan banyak hal yang harus disampaikan kepada masyarakat.

2. Pelaksanaan sosialisasi selama ini dilakukan dengan pola desentralisasi. Hal ini justru melemahkan fungsi sosialisasi yang seharusnya seragam. Pengumuman tentang struktur dan alur pelayanan kesehatan berjalan sendiri-sendiri di daerah masing-masing, dengan media masing-masing.

3. Dinas Kesehatan Provinsi Jawa Barat belum sepenuhnya melakukan sosialisasi dengan dukungan kebijakan berupa kebijakan umum, petunjuk pelaksana dan petunjuk teknis pelaksanaan pelayanan kesehatan masyarakat, terutama tentang kesehatan ibu dan anak, kepada masyarakat. Kurang jelasnya kebijakan umum dan petunjuk pelaksana teknis kesehatan masyarakat telah membingungkan para stakeholder, terutama yang bekerja sama seperti BPJS Kesehatan dari pihak swasta dan para pengguna dari masyarakat.

4. Agar sosialisasi tentang struktur pelayanan kesehatan ibu dan anak dapat terlaksana dengan baik, perlu didukung oleh berbagai media, termasuk media sosial dan media tradisional.

\section{DAFTAR PUSTAKA}

Anwar, R.K., Rusmana, A. and Rahman, M.T., 2018. The Politics Of Information On Traditional Medical Practices In Bandung Barat. MIMBAR, Jurnal Sosial dan Pembangunan, 34(1).

Azwar, Azrul. 1996. Pengantar Administrasi Kesehatan. Jakarta: Binarupa Aksara. 
Borg, Walter R. and Meredith D. Gall. 1989. An Overview of Educational Research. London: Longman.

Buku Pegangan Sosialisasi Jaminan Kesehatan Nasional (JKN) dalam Sistem Jaminan Sosial Nasional. 2013. Kementerian Kesehatan Republik Indonesia.

Creswell, John. W. 2012. Research Design Qualitative \& Quantitative Approaches. $9^{\text {th }}$ edition. Thousand Oaks, CA: Sage Publication.

Chotim, E. R. (2018). KEBIJAKAN BANDUNG TRANSIT AREA (BTA) UNTUK PENINGKATAN KUNJUNGAN WISATA. TEMALI: Jurnal Pembangunan Sosial, 1(1), 33-57.

Denzin, Norman K and Yvonna S. Lincoln. 1994. Handbook of Qualitative Research. Thousand Oaks, CA: Sage Publications.

Dever, G.E. Alan. 1984. Epidemiology in Health Services Management. Madrid: Aspen.

Indonesia, J., 2015. Fungsi, tugas dan wewenang BPJS.

Dulkiah, M. (2017). The Impact of Cash Transfer on Family's attitude and Copying Mecanism. JISPO: Jurnal Ilmu Sosial dan Ilmu Politik, 7(1), 102-112.

Kesehatan, B.P.J.S., 2014. Panduan Layanan Bagi Peserta BPJS Kesehatan. Jakarta: Kementerian Kesehatan RI.

Locke, L.; Silverman, S.; Spirduso, W.W. 1987. Reading and Understanding Research. Thousand Oaks, CA: Sage Publications.

Marshall, Catherine and Rossman, Gretchen B. 1989. Designing Qualitative Research. Newbury Park, CA: Sage Publications.

Miles, M.B. and Huberman, A.M. 1994. Qualitative Data Analysis: An Expanded Sourcebook. $2^{\text {nd }}$ edition. Thousand Oaks, CA: Sage Publications.

Mulyadi, Mohammad. 2014. Info Singkat: Sosialisasi Ketentuan Jaminan Sosial 2014. Jakarta: P3DI Setjen DPR RI.

Peraturan Menteri Kesehatan Nomor 741/MENKES/PER/VII/2008 tentang Standar Pelayanan Minimal Bidang Kesehatan.

Sari, A. L. (2017). THE ROLE OF SOCIAL WORKERS IN THE DEVELOPMENT OF TOURISM VILLAGES. JISPO: Jurnal Ilmu Sosial dan Ilmu Politik, 7(2), 1-23. 
Sugyati, C., Mariana, D. and Sjoraida, D.F., 2018, March. The position of the targets of the public health policy of maternal and child in Bandung. In IOP Conference Series: Earth and Environmental Science (Vol. 126, No. 1, p. 012058). IOP Publishing.

Undang-Undang Nomor 23 Tahun 2014 tentang Pemerintahan Daerah.

Undang-Undang Nomor 36 Tahun 2009 tentang Kesehatan. 